Article

\title{
Enhancing Eco-Efficiency of Agro-Products' Closed-Loop Supply Chain under the Belt and Road Initiatives: A System Dynamics Approach
}

\author{
Rui Zhao ${ }^{1,2}$, Yiyun Liu ${ }^{1}$, Zhenyan Zhang ${ }^{3}$, Sidai Guo ${ }^{2}$, Ming-Lang Tseng ${ }^{4}$ and Kuo-Jui Wu ${ }^{5, *(1)}$ \\ 1 Faculty of Geosciences and Environmental Engineering, Southwest Jiaotong University, \\ Chengdu 611756, China; ruizhaoswjtu@hotmail.com (R.Z.); 18328036686@163.com (Y.L.) \\ 2 Sichuan Province Cyclic Economy Research Centre, Southwest University of Science and Technology, \\ Mianyang 621010, China; guosidai@126.com \\ 3 School of Transportation and Logistics, Southwest Jiaotong University, Chengdu 610031, China; \\ zhangzhenyan96@163.com \\ 4 Institute of Innovation and Circular Economy, Asia University, Taichung 41354, Taiwan; \\ tsengminglang@gmail.com \\ 5 School of Business, Dalian University of Technology, Panjin 124221, China \\ * Correspondence: wukuojui@dlut.edu.cn
}

Received: 26 January 2018; Accepted: 27 February 2018; Published: 1 March 2018

\begin{abstract}
This study redesigns the supply chain of agricultural products in southwest China under the Belt and Road Initiative to improve its eco-efficiency by considering the associated agro-wastes flowing into bioenergy enterprise for energy production. Two scenarios are created, in which the first assumes that all waste flows into the enterprise, whereas the second only considers the inflow of agro-waste produced by farmers and the wholesale market. A system dynamics simulation is conducted by using carbon emissions per product as an indicator to obtain the optimal scenario for managerial practice and design an incentivizing mechanism to drive supply chain operations. A case study is provided to demonstrate application of the system dynamics. Finally, the limitations of the study are discussed to lay the foundation for further improvement.
\end{abstract}

Keywords: supply chain management; eco-efficiency; closed-loop; system dynamics; agro-products

\section{Introduction}

Since its launch in 2013, the Belt and Road Initiative has been emphasizing green cooperation among the involved countries to highlight low carbon characteristics of the domestic and overseas supply chain and enhance the value added to products [1,2]. Most countries involved in this initiative are emerging and developing economic entities, where agriculture is a leading industry in their national economies [3]. Nevertheless, their agro-product supply chains usually have low eco-efficiencies, which leads to less utilization of agro-waste, thus having an impact on the formulation of reverse logistics $[4,5]$. As these agro-wastes generally contain large amounts of biomasses, recycling them for energy recovery may yield greater economic and environmental benefits [6-8]. However, the incorporation of bioenergy enterprises into the supply chain inevitably disturbs supply chain operations. For instance, it may increase the number of stakeholders involved, hence complicating the coordination of the supply chain network [9]. Meanwhile, additional costs including the cost of agro-waste collection, pretreatment, and transportation may be incurred, causing an impact on the value added to the supply chain $[10,11]$.

This study aims at redesigning the conventional agro-product supply chain to improve its eco-efficiency by considering the associated agro-waste flowing into bioenergy enterprise for energy production. Two operations scenarios are established, using system dynamics simulation to select 
the optimal scenario to enhance eco-efficiency for the proposed supply chain. In addition, an optimal policy mechanism is developed to put the optimal scenario into supply chain management practice, thus enhancing its sustainability. There are three contributions within this study: first, this study takes the concept of sustainability into account for the agro-product supply chain with consideration to its eco-efficiency; second, system dynamics enable us to offer a visual analysis for agribusinesses to realize their critical processes; third, the analytical results provide the evidence to guide agribusiness in improving their current performance toward sustainability under the Belt and Road Initiatives.

The remaining parts of this study are organized as follows: Section 2 presents the literature reviews. Section 3 presents the method conceptualization and formulation. Results are discussed in Section 4. Section 5 addresses the implications. Lastly, conclusions and research limitations are expressed in Section 6.

\section{Theoretical Background}

Conventional optimization of the agro-product supply chain focuses on how to increase the economic benefits. Xiao et al. [12] applied the CIF (Cost Insurance and Freight) business model to investigate the impacts of transport delay, price, and freshness of agro-products on the supply chain, consequently devising a cost-sharing mechanism to enhance its associated economic benefits. Pathumnakul et al. [13] further considered the factors of technical maturity and seasonal market demands, in turn optimizing the supply chain of fresh shrimps in Thailand to minimize the storage cost. With regard to uncertainties in productivity, Bohle et al. [14] applied robust optimization to the supply chain of wine grapes and developed an optimal grape harvesting scheduling. Similarly, Paksoy et al. [15] considered production, transport capacity, and the uncertainties in market demand to optimize the edible vegetable oil supply chain. Owing to the perishable nature of agro-products, De Keizer et al. [16] combined multi-objective optimization and discrete event simulation to redesign the supply chain and reduce the financial risk. Soto-Silva et al. [17] further optimized the coordination mechanism of the agro-product supply chain to mitigate the decay of agro-products.

With the emergence of low-carbon agriculture, carbon emissions have been gradually incorporated into the decision-making and optimization of the agro-product supply chain as an important indicator to enhance eco-efficiency. Soysal et al. [18] used a beef supply chain as an example to investigate the influences of road structure, vehicle and fuel types, weight loads of vehicles, and traveled distances on the carbon emissions of the supply chain. Similar studies were conducted by Accorsi et al. [19] and Chandrasekaran et al. [20], who aimed to minimize carbon emissions during logistic processes to optimize the logistics network structure of the potato supply chain. On the other hand, Jonker et al. [21] shed light on the greenhouse gas (GHG) emission intensity of the biomass supply chain of sugarcane ethanol production by optimizing the sizes and locations of enterprises. Meanwhile, Miranda-Ackerman and Azzaro-Pantel [22] incorporated the net present value (NPV) and investment (I), global warming potential (GWP), and average variable unit cost (AVUC) as the objective functions to construct a multi-objective model, revising the location, allocation of resources, and production capacity of the supply chain of orange juice production.

In recent years, the agro-product supply chain has inclined toward a closed-loop transition (i.e., optimization based upon a lifecycle assessment) to reinforce its sustainability [23]. Using the closed-loop tangerine supply chain of a Korean brand, Kim et al. [24] designed the optimal structure of the closed-loop supply chain based upon returnable transport items (RTIs). Similarly, Turki et al. [25] optimized a closed-loop supply chain, by taking a combination of manufacturing, remanufacturing, transport, and warehousing into account. Zabaniotou et al. [26] discussed the example of the closed-loop supply chain of small-scale olive oil production and proposed a symbiosis approach to transform waste into energy sources. Banasik et al. [27] constructed a closed-loop supply chain of the mushroom industry and optimized the cost and environmental impact of mushroom cultivation through a multi-objective model. 
Since most of the above studies targeted optimizing the network of an existing supply chain structure, they lacked a comparison among different supply chain operation patterns and discussion on the policy design postoptimization. Therefore, this study adopts system dynamics modeling and proposes different operational scenarios of the agro-product supply chain to select the optimal scenario based upon carbon emissions per unit product. This is followed by a discussion on the incentive policies to facilitate the operation of the optimal scenario.

\section{Method}

\subsection{Model Conceptualization}

A simplified agro-product supply chain comprises farmers, market, consumers, and a municipal waste disposal center. Farmers are mainly responsible for agricultural production. The "market" indicates a retailer of a large-scale wholesale market, who purchases agro-products at a market price and sell them to the consumers (i.e., urban residents). The agro-wastes from the farmers, retailers, and consumers are sent to the municipal landfill for ultimate disposal. Due to bringing bioenergy enterprises into the supply chain network, agro-wastes may be recovered for energy production. Their power generation is merged into the local grid system to provide renewable energy consumed by urban residents (consumers) and farmers, to reduce waste disposal in landfills and promote energy savings.

To explore the optimal pattern for supply chain operations against this background, two scenarios are fabricated in this study: in Supply Chain 1, all the agro-wastes produced by farmers, market, and consumers proceed to the bioenergy enterprise for processing as shown in Figure 1a; in Supply Chain 2, agro-wastes produced by consumers are sent to the landfill, whereas the wastes produced by farmers and the market enter the bioenergy enterprise as shown in Figure 1b. Compared with Scenario 1, the latter is set based upon possible complexities involved in waste classification and pretreatment because of consumers' individual rationalities which may result in less efficiency in agro-waste collection.

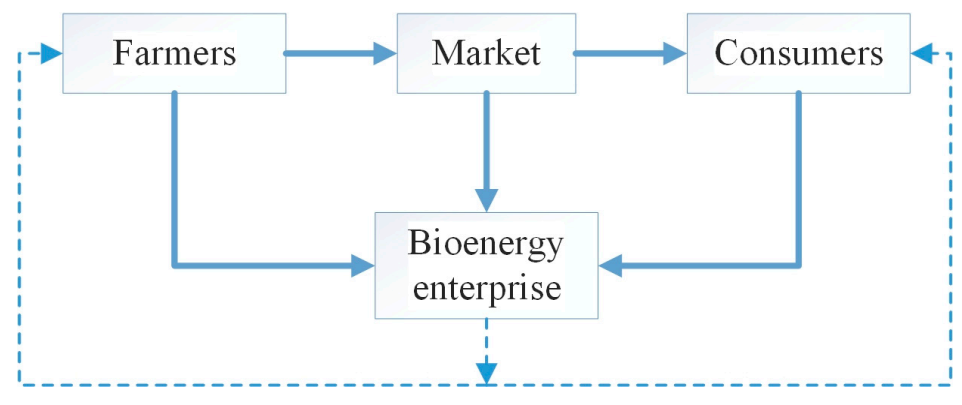

(a)

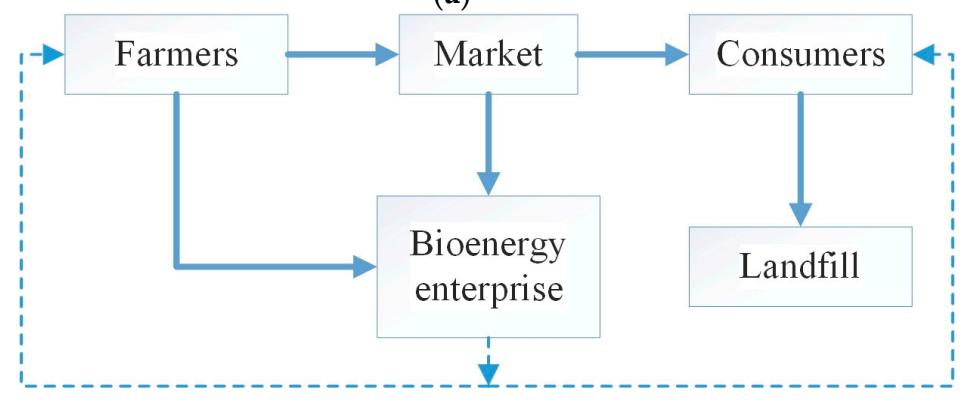

(b)

Figure 1. Scenarios of the redesigned supply chain network. (a) Scenario 1 of the redesigned supply chain; (b) Scenario 2 of the redesigned supply chain. 
The modeling process usually entails four basic steps: structural analysis of the system, causal loop diagram drawing, stock and flow diagram drafting, and model validation $[28,29]$. To determine the key factors of the system and grasp their interrelations, the following hypotheses regarding the supply chain design are proposed:

1. The prices of the same product do not vary significantly in different commercial regions;

2. The locations of the farms and the market as well as the logistic routes between different supply chain nodes are relatively stable;

3. The supply chain only concerns the mobility of a single type of product.

\subsection{Model Formulation}

A casual loop diagram is drawn to illustrate the system structure and the interrelation among key factors. In Figure 2, there are two reinforcing loops and three balancing loops. The first reinforcing loop shows the increase in agro-wastes and the consequent increase in total agro-wastes due to increased market acquisition, which leads to a higher production of biomass energy and a lower consumption of traditional energies; this reduces the supply cost and eventually encourages more market acquisition. As for the second reinforcing loop, the increased production of agro-products leads to more agro-wastes and more total wastes; this stimulates biomass energy production and lowers the farmers' consumption of traditional energies, in turn reducing the supply cost and expanding the production of agro-products.

In terms of the balancing loops, the first pertains to the increased energy consumption caused by increased market acquisitions; this results in greater energy use and higher overall cost of the supply chain, in turn shrinking the amount of market acquisitions. The second balancing loop examines the decreased stock of agro-products due to increased market acquisitions, followed by a reduced production of agro-wastes and, thus, biomass energy; as a result, the use of traditional energy increases, increasing the overall cost and, eventually, lowering the number of market acquisitions. The last balancing loop is about the increase in the stock of agro-products due to increased market acquisitions; this leads to the increased use of traditional energies and then a higher supply cost, reducing the market acquisitions.

Based on the above analyses, two-feedback-loop clusters are defined as follows:

Reinforcing loop clusters: Marketing acquisition $\rightarrow$ Marketing waste generation $\rightarrow$ Total waste generation $\rightarrow$ Recycling amount of bioenergy plant $\rightarrow$ Conventional energy consumption $\rightarrow$ Cost of energy use $\rightarrow$ Marketing acquisition; Farmers' agro-production $\rightarrow$ Waste generation in farming stage $\rightarrow$ Total waste generation $\rightarrow$ Recycling amount of bioenergy plant $\rightarrow$ Conventional energy consumption $\rightarrow$ Cost of energy use $\rightarrow$ Farmers' agro-production.

Balancing loop clusters: Marketing acquisition $\rightarrow$ Stock in farmers' agro-production $\rightarrow$ Waste generation in farming stage $\rightarrow$ Total waste generation $\rightarrow$ Recycling amount of bioenergy plant $\rightarrow$ Conventional energy consumption $\rightarrow$ Cost of energy use $\rightarrow$ Marketing acquisition; Marketing acquisition $\rightarrow$ Energy consumption in Marketing acquisition $\rightarrow$ Conventional energy consumption $\rightarrow$ Cost of energy use $\rightarrow$ Marketing acquisition; Marketing acquisition $\rightarrow$ Stock of agro-products in marketing stage $\rightarrow$ Conventional energy consumption $\rightarrow$ Cost of energy use $\rightarrow$ Marketing acquisition.

With reference to the causal loop diagram, this study adopts Vensim 6.0 to compose a stock and flow diagram to quantify the interrelation among the key variables as shown in Figure 3. These variables can be divided into three groups: state, rate, and auxiliary variables. State variables are factors that are cumulative over time [29], such as the inventory of agro-products. Rate variables are integrals representing the difference between the input and output rates with respect to time [29]. An example is the integral difference between the stock of agro-products plus the rate of agro-product production and the rate of market acquisition. Auxiliary variables are the intermediates between state and rate variables [29]. An example is the variance of carbon emissions. All variables used in 
the model and their corresponding categories are listed in Table 1. The detailed system dynamics equations are shown in the Appendix A.

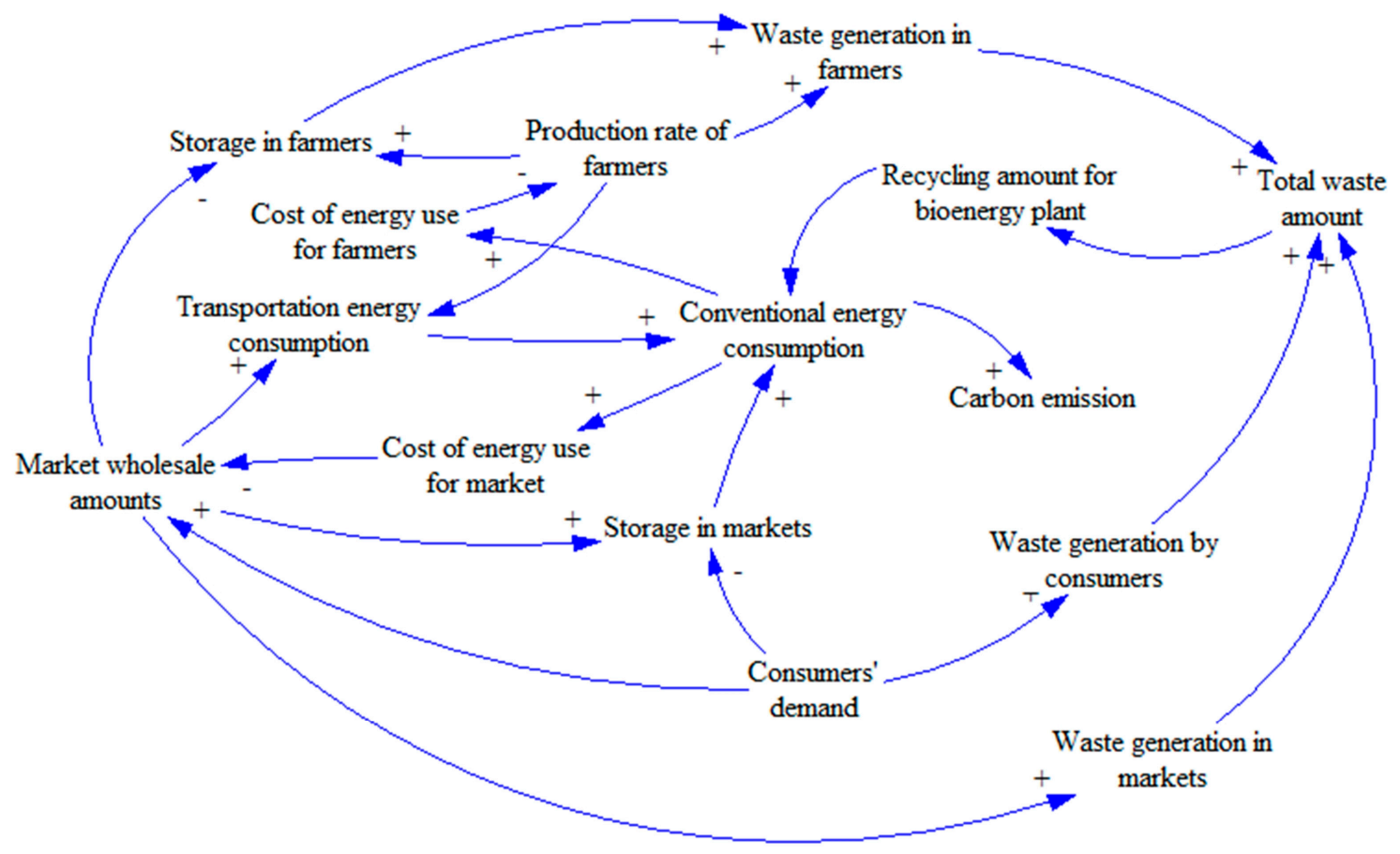

Figure 2. Causal loop diagram of the agro-product supply chain.

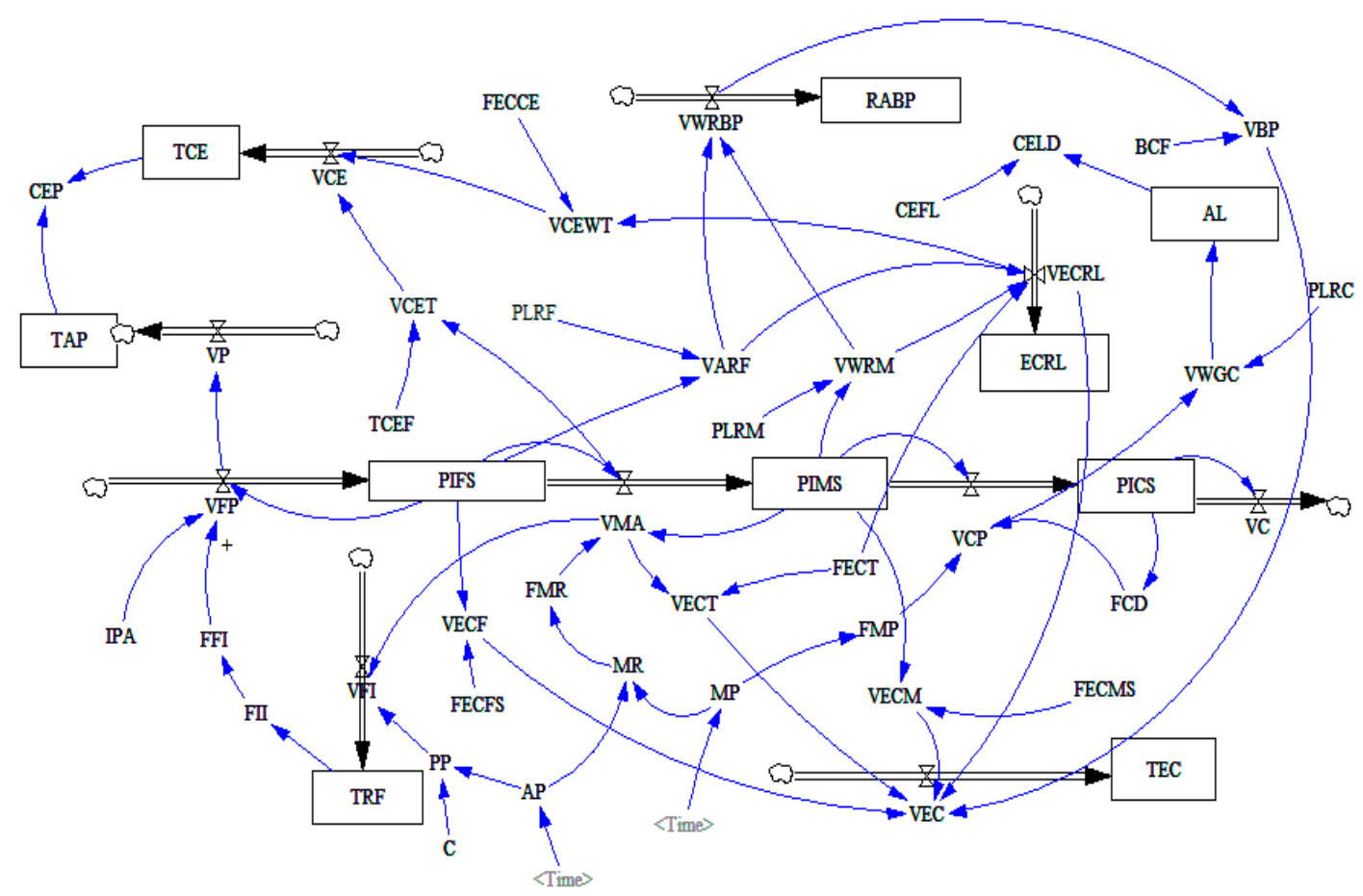

Figure 3. Stock and flow diagram of the agro-product supply chain. 
Table 1. Key variables of the system dynamics (SD) model.

\begin{tabular}{|c|c|c|}
\hline Key Variable & Variable Type & Input/Output \\
\hline $\mathrm{C}($ Cost $)$ & Constant & Input \\
\hline FECFS (Factor of Energy Consumption in Farming Stage) & Constant & Input \\
\hline FECT (Factor of Energy Consumption in Transportation) & Constant & Input \\
\hline FECMS (Factor of Energy Consumption in Marketing Stage) & Constant & Input \\
\hline FECCE (Factor of Energy Consumption Converted into Carbon Emissions) & Constant & Input \\
\hline CEFL (Carbon Emissions Factor of Landfill Disposal) & Constant & Input \\
\hline BCF (Biomass-to-Energy Conversion Factor) & Constant & Input \\
\hline TCEF (Factor of Carbon Emissions in Transportation) & Constant & Input \\
\hline PLRF (Product Loss Rate in Farming Stage) & Rate & Input \\
\hline PLRM (Product Loss Rate in Marketing Stage) & Rate & Input \\
\hline PLRC (Product Loss Rate of Consuming Stage) & Rate & Input \\
\hline IPA (Initial Production of Agro-Products) & Constant & Input \\
\hline FMR (Factor of Marketing Revenue) & Constant & Input \\
\hline $\mathrm{AP}$ (Acquisition Price) & Constant & Input \\
\hline MP (Marketing Price) & Constant & Input \\
\hline PIFS (Product Inventory in Farming Stage) & State & Output \\
\hline PIMS (Product Inventory in Marketing Stage) & State & Output \\
\hline PICS (Product Inventory in Consuming Stage) & State & Output \\
\hline AL (Amount of Landfill Disposal) & State & Output \\
\hline TAP (Total Amount of Products) & State & Output \\
\hline TCE (Total Carbon Emissions) & State & Output \\
\hline TRF (Total Revenue of Farmers) & State & Output \\
\hline RABP (Recycling Amount of Bioenergy Plant) & State & Output \\
\hline ECRL (Energy Consumption of Reverse Logistics) & State & Output \\
\hline TEC (Total Energy Consumption) & State & Output \\
\hline VECT (Variation of Energy Consumption in Transportation) & Auxiliary & Output \\
\hline VECF (Variation of Energy Consumption in Farming Stage) & Auxiliary & Output \\
\hline VECM (Variation of Energy Consumption in Marketing Stage) & Auxiliary & Output \\
\hline CEP (Carbon Emissions Per Product) & Auxiliary & Output \\
\hline PP (Profit Per Product) & Auxiliary & Output \\
\hline MR (Market Revenue) & Auxiliary & Output \\
\hline FII (Farmers' Income Index) & Auxiliary & Output \\
\hline FFI (Factor of Farmers' Income) & Auxiliary & Output \\
\hline FMP (Factor for Marketing Price) & Auxiliary & Output \\
\hline FCD (Factor of Consumers' Demand) & Auxiliary & Output \\
\hline VFP (Variation of Farmers' Production) & Auxiliary & Output \\
\hline VMA (Variation of Marketing Acquisition) & Auxiliary & Output \\
\hline VCP (Variation of Consumers' Purchasing) & Auxiliary & Output \\
\hline VC (Variation Consumption) & Auxiliary & Output \\
\hline VFI (Variation of Farmers' Income) & Auxiliary & Output \\
\hline VP (Variation of Total Products) & Auxiliary & Output \\
\hline VCE (Variation of Carbon Emissions) & Auxiliary & Output \\
\hline VWRBP (Variation of Waste Recycling by Bioenergy Plant) & Auxiliary & Output \\
\hline VCEWT (Variation of Carbon Emissions in Waste Transportation) & Auxiliary & Output \\
\hline VCET (Variation of Carbon Emissions in Transportation) & Auxiliary & Output \\
\hline VARF (Variation of Agro-Waste Recycling from Farmers) & Auxiliary & Output \\
\hline VWRM (Variation of Waste Recycling from Market) & Auxiliary & Output \\
\hline VCEL (Variation of Carbon Emissions in Landfill Disposal) & Auxiliary & Output \\
\hline VWGC (Variation of Waste Generation in Consuming Stage) & Auxiliary & Output \\
\hline VBP (Variation of Bioenergy Production) & Auxiliary & Output \\
\hline CELD (Carbon Emissions of Landfill Disposal) & Auxiliary & Output \\
\hline VECRL (Variation of Energy Consumption of Reverse Logistics) & Auxiliary & Output \\
\hline VEC (Variation of Energy Consumption) & Auxiliary & Output \\
\hline
\end{tabular}

\section{Results and Discussions}

\subsection{Case Background}

This study uses yellow chives, which are often seen in southwest China, as typical agro-products for our case study. Due to substantial market demand, an industrial pattern of large-scale chive 
production has been established. The supply chain comprises a production base, a large-scale wholesale market of agro-products, main consuming towns in the neighborhood, a landfill for household waste, and a bioenergy enterprise. Their geographical locations are illustrated in Figure 4. The production base of the yellow chives is the biggest in southwest China, located in the city of Chengdu in the Sichuan province, and produces more than 8000 tons annually with a sales volume of approximately 16 million RMB and a damage rate of around $20-30 \%$. The damaged produce is transported to a nearby landfill that processes urban household wastes. As the concept of green supply chain management is put into practice, the agro-wastes from the production base are integrated with the surrounding bioenergy enterprises to enhance the utilization of agro-waste and reduce energy consumption.

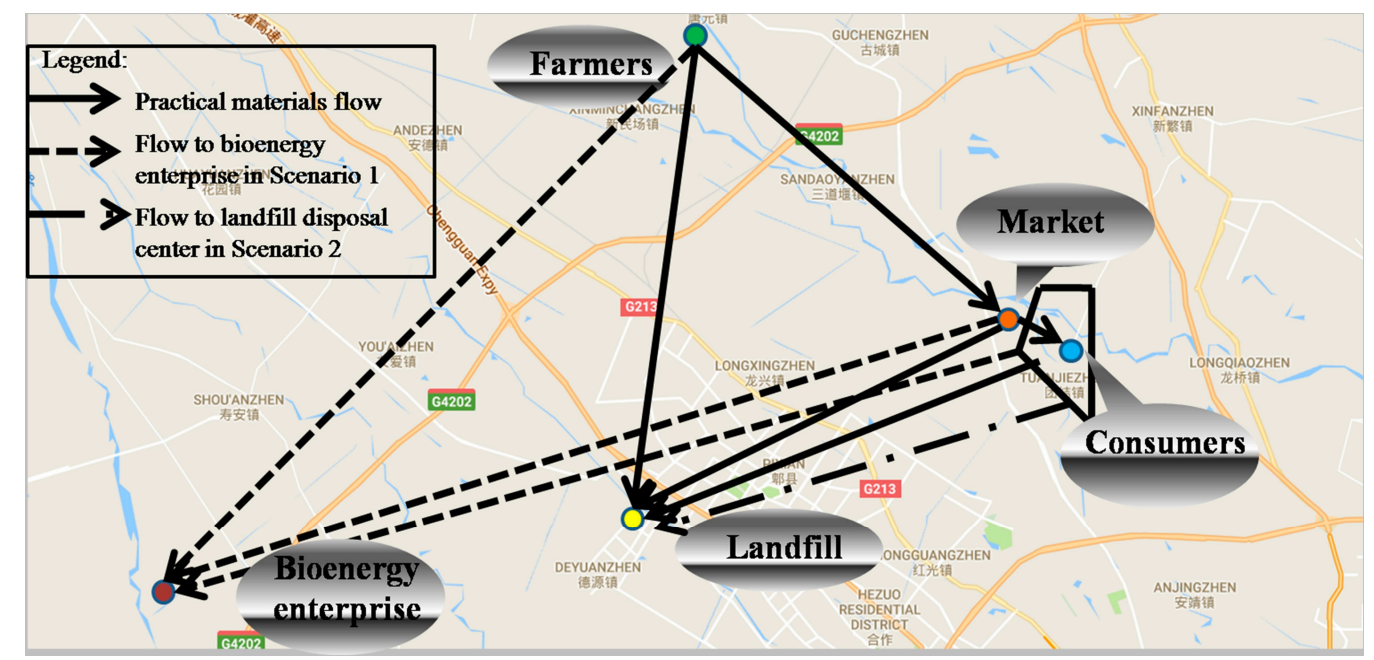

Figure 4. Geographical locations of the Case Study.

The data in this study is mainly collected through field investigation and review of related statistics. Two types of parameters are involved in the model. The first involves quantifiable, determinable parameters obtained either through investigation, such as the market price of yellow chives, or from previous literature, such as the carbon emissions of supply chain activities. The other group contains parameters that are difficult to quantify, such as the influences of income and the damage rates of agro-products at different stages of the supply chain, which are mainly obtained by the Delphi method and interviews with experts. The detailed parameters are listed in Table 2.

Table 2. Measurements of the model input.

\begin{tabular}{|c|c|c|}
\hline Variable & Value & Source \\
\hline Cost $(\mathrm{C})$ & 0.72 Yuan $/ \mathrm{kg}$ & Field investigation \\
\hline FECFS (Factor of Energy Consumption in Farming Stage) & $0.0018 \mathrm{~kg}$ diesel $/(\mathrm{kg} \cdot$ day $)$ & Field investigation \\
\hline FECMS (Factor of Energy Consumption in Marketing Stage) & $0.0044 \mathrm{~kg}$ diesel $/(\mathrm{kg} \cdot$ day) & Field investigation \\
\hline FECCE (Factor of Energy Consumption Converted into Carbon Emissions) & 3.1388 & IPCC $[30]$ \\
\hline TCEF (Factor of Carbon Emissions in Transportation) & $0.0347 \mathrm{~kg} \mathrm{CO} / \mathrm{kg} \cdot 100 \mathrm{~km}$ & Patel and Kumar [31] \\
\hline PLRC (Products Loss Rate of Consuming Stage) & 0.3 & Delphi method \\
\hline FECT (Factor of Energy Consumption in Transportation) & $0.011 \mathrm{~kg}$ diesel $/ \mathrm{kg} \cdot 100 \mathrm{~km}$ & Giordano et al. [32] \\
\hline CEFL (Carbon Emissions Factor of Landfill Disposal) & $0.2708 \mathrm{~kg} \mathrm{CO} 2 / \mathrm{kg}$ waste & Lee et al. [33] \\
\hline BCF (Biomass-to-Energy Conversion Factor) & $0.007 \mathrm{~kg}$ diesel $/ \mathrm{kg}$ recycled waste & AI-Hamamre et al. [8] \\
\hline PLRF (Products Loss Rate in Farming Stage) & 0.25 & Delphi method \\
\hline PLRM (Products Loss Rate in Marketing Stage) & 0.1 & Delphi method \\
\hline
\end{tabular}

\subsection{Model Validation}

Prior to the system dynamics simulation, it is necessary to validate the constructed model to test its effectiveness in reflecting reality. There are typically two typical methods to ensure the model accuracy, i.e., behavior sensitivity analysis and historical data comparison, to verify the extent to which the model is consistent with the actual situation [34,35]. In this study, the latter is used to test the model 
performance, through comparing the discrepancies between the simulated and actual values through error analysis of the model, in turn quantifying the accuracy of the model. The common practice is to check whether the simulation result of a certain quantitative variable is in accordance with the corresponding historical data, e.g., the total income of farmers. The simulation result is compared against the actual statistics of the farmers' income in the past few years. Table 3 reflects the differences between the simulation results and the historical statistics for the past seven years, for which the average relative error is shown as $3.93 \%$. The error is considered within $15 \%$, which validates the reliability of the presented model [36].

Table 3. Comparison of simulated and historical values of farmers' income.

\begin{tabular}{cccccccc}
\hline \multirow{2}{*}{ Farmers' Income } & $\mathbf{2 0 1 0}$ & $\mathbf{2 0 1 1}$ & $\mathbf{2 0 1 2}$ & $\mathbf{2 0 1 3}$ & $\mathbf{2 0 1 4}$ & $\mathbf{2 0 1 5}$ & $\mathbf{2 0 1 6}$ \\
\cline { 2 - 7 } & \multicolumn{7}{c}{ (Ten Thousand Yuan) } \\
\hline Simulation result & 206.79 & 220.01 & 206.19 & 221.34 & 216.33 & 220.48 & 217.23 \\
Statistical data & 205.12 & 214.32 & 220.67 & 212.83 & 230.59 & 225.34 & 229.03 \\
Relative error & $0.81 \%$ & $2.65 \%$ & $6.56 \%$ & $4.00 \%$ & $6.18 \%$ & $2.16 \%$ & $5.15 \%$ \\
\hline
\end{tabular}

\subsection{Benchmark Scenario}

In the benchmark scenario, the bioenergy enterprises are excluded from the supply chain activities, and all the agro-wastes are delivered to the landfill that processes urban household wastes. Using 10 years as one simulation cycle, the simulation results of the carbon emissions per unit product in the benchmark scenario are shown in Figure 5.

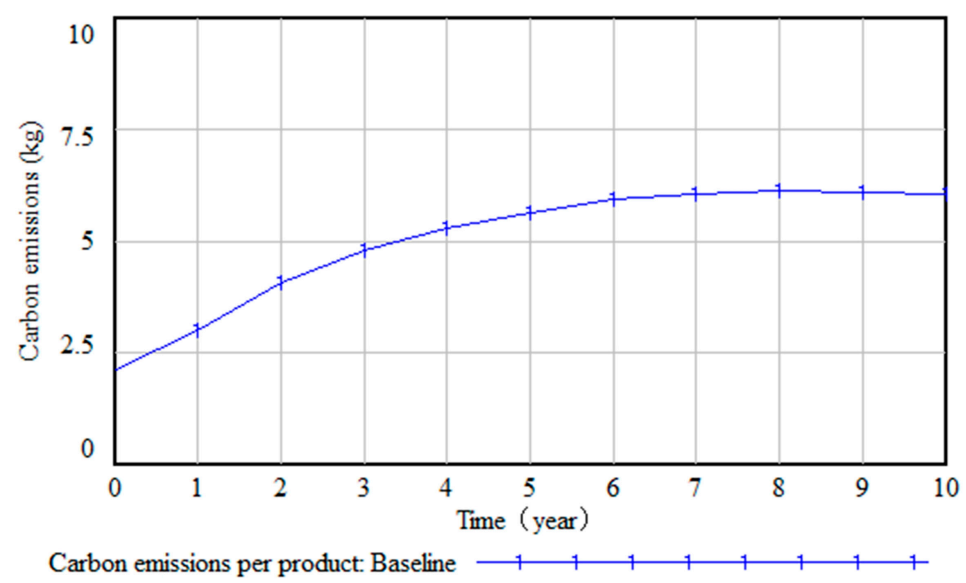

Figure 5. Carbon emissions per unit product in the benchmark scenario.

\subsection{Scenario Selection}

Figure 6 reflects the simulation results of the carbon emissions per unit agro-product under the two proposed scenarios. Compared with the benchmark scenario, both scenarios exhibit a significant decline of carbon emissions during the simulation cycle. Scenario 1 produces a cumulative decrease of $14.13 \%$, whereas Scenario 2 shows a cumulative decrease of $18.02 \%$. It is evident that Scenario 2 is more effective in reducing carbon emissions. This conclusion indicates that although recycling and processing agro-wastes generates a greater amount of bioenergy, this approach is undesirable because the dispersion of consumers contributes to an increase in carbon emissions during waste collection and transport and, consequently, an increase in total emissions. 


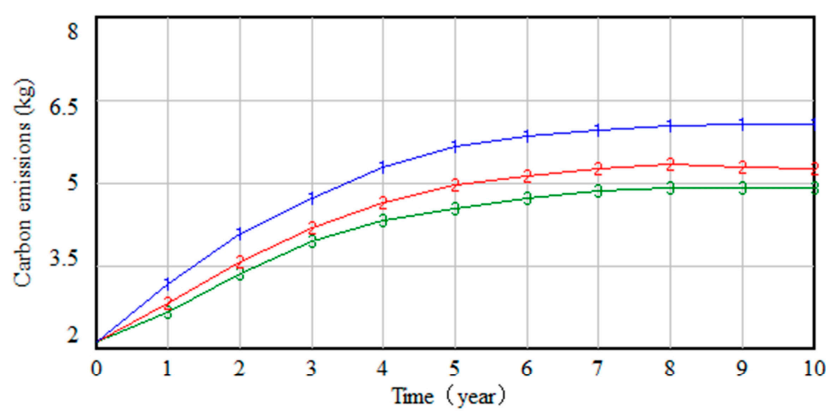

Carbon emissions of per product: Baseline $\begin{array}{rlllllll}1 & 1 & 1 & 1 & 1 & 1 & 1 & 1\end{array}$

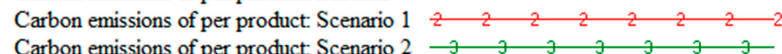

Figure 6. Carbon emissions per unit product under two scenarios.

\subsection{Development of Incentive Policies}

The above analysis shows that, despite the substantial environmental benefits brought about by a green supply chain, the energy production of the bioenergy enterprises is relatively small due to external costs produced by measures for energy savings and emission reductions. The wide dispersion of the agro-wastes leads to high costs of waste collection and logistics, which cripple the management and implementation of the agro-product supply chain. Under this context, government measures such as subsidies, green procurement, and tax incentives serve an important role in maintaining the stable operations of a green supply chain. Given that Scenario 2 has been chosen as the preferred operation mode, this section identifies the optimal incentive mechanism by observing how government subsidies influence the emissions reduction of the supply chain.

\subsubsection{Government Subsidies for Bioenergy Enterprise}

Government investments and subsidies are effective in helping bioenergy enterprises improve their operations and development [37]. This study assumes that, after subsidization, the bioenergy enterprises will be able to choose a high-cost cleaner production plan to boost their energy conversion efficiency to three times the original. Under such a context, the simulation results indicate an insignificant drop in carbon emissions per unit product of 6.05\%, as shown in Figure 7.

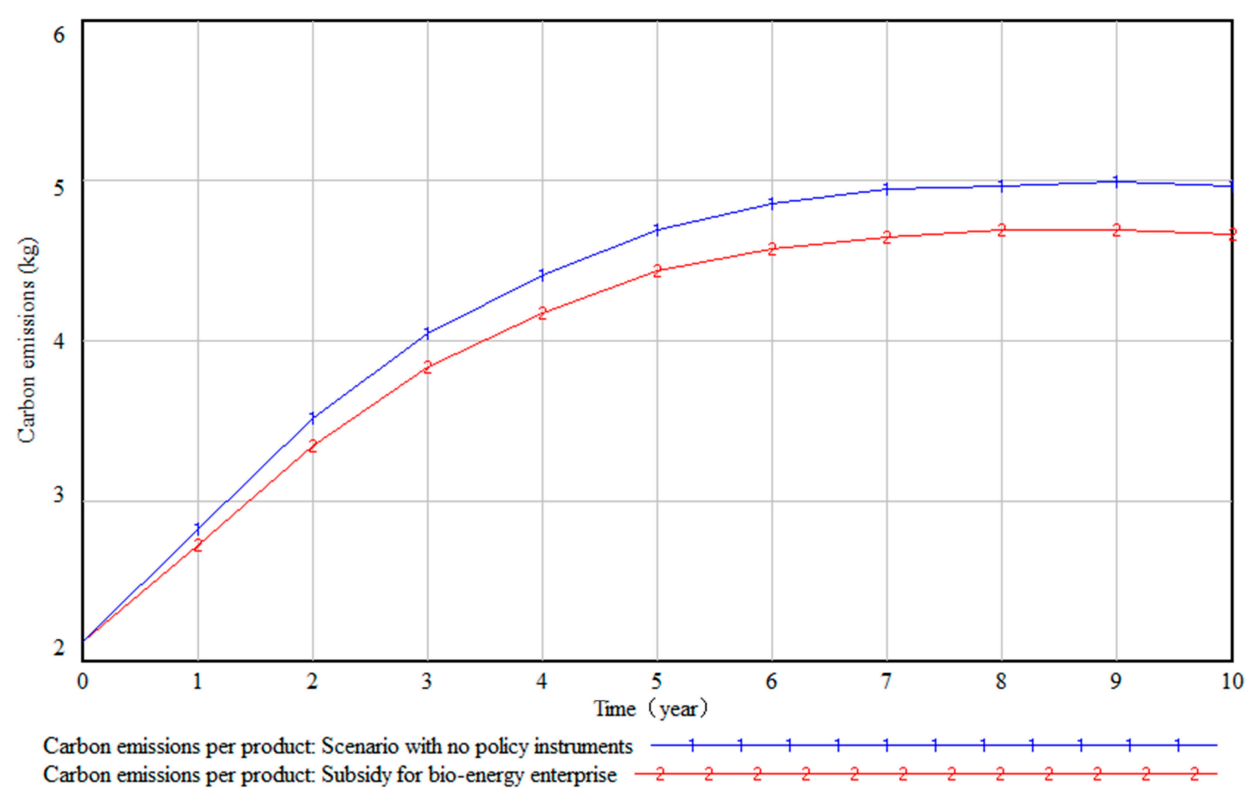

Figure 7. Carbon emissions per unit product under subsidization of bioenergy enterprises. 


\subsubsection{Logistic Subsidies}

In this scenario, the government considers subsidizing logistics to stimulate the transport processes in the supply chain to shift from fossil energy driven to renewable energy driven. According to Figure 8, the carbon emissions per unit product in this scenario decline by $11.29 \%$. Compared with subsidizing the bioenergy enterprises, logistic subsidies have significantly more economic and environmental benefits. Therefore, any attempt to optimize the agro-product supply chain may give priority to emissions reduction at the logistic stages.

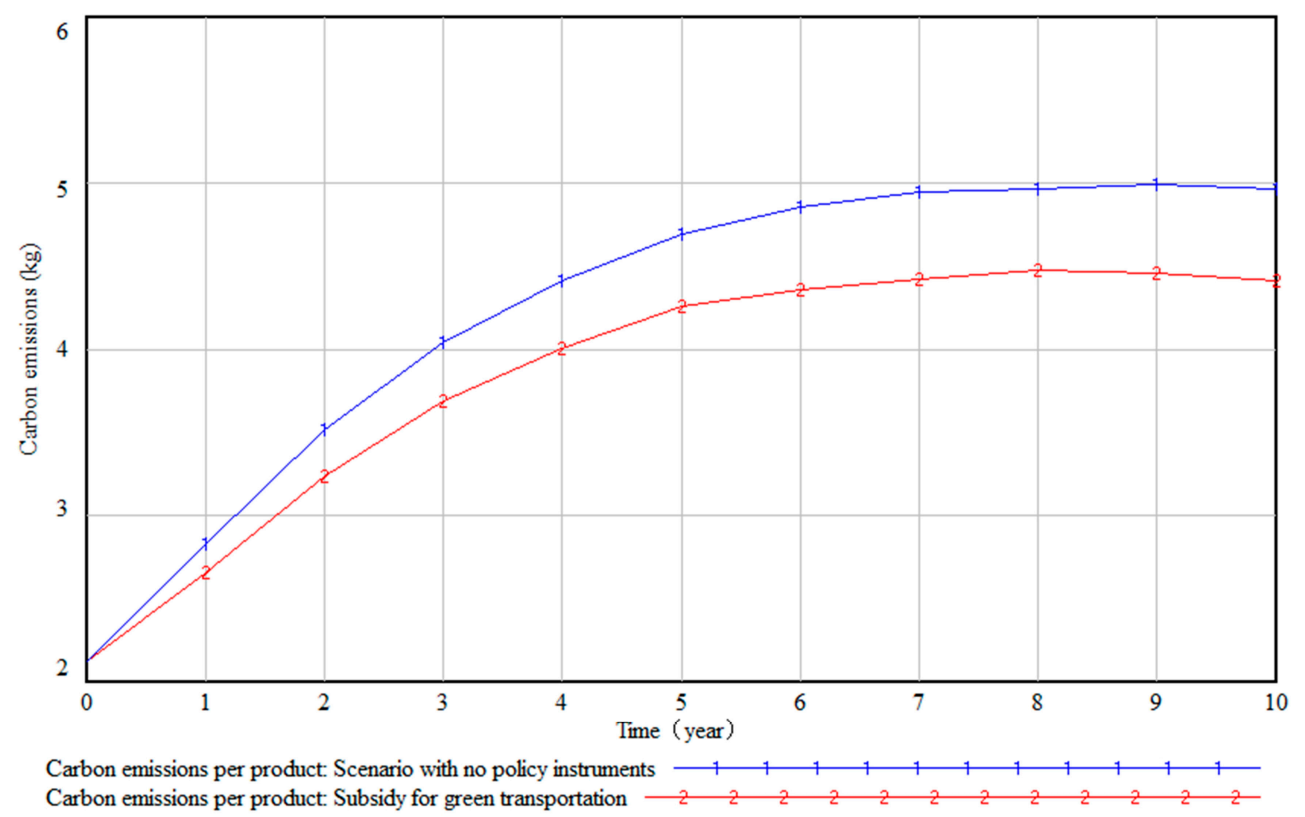

Figure 8. Carbon emissions per unit product under logistic subsidization.

\section{Implications}

The case example is used to demonstrate the application of system dynamics, which is employed to select an operations scenario for supply chain management practice to enhance its eco-efficiency, by using carbon emissions per unit product as the indicator for simulation. The results also provide insight into improvement of agro-product supply chain management of countries along the Belt and Road routes. For instance, subsidizing the logistic processes can effectively lower emission intensity. This is also an indirect proof that the carbon emissions of the agro-product supply chain largely originate from the logistic processes [38]. In comparison, subsidizing bioenergy enterprise is ineffective in terms of emission reduction. This finding indirectly verifies the research conclusion by Yue et al. [39], who state that the lack of a systematic coordination mechanism within bioenergy enterprises has hindered their electricity generation capacity and industrial scale, in turn limiting the benefits of introducing high-efficiency energy conversion technologies for reducing carbon emissions. Therefore, we suggest that sufficient consideration should be given to the coordination and balance among stakeholders of a supply chain, while bioenergy enterprises should be industrialized and expanded to a certain scale to gradually highlight their market competitiveness and eco-efficiency.

There are several uncertainties in this study. First, choosing different types of supply chains during the case study to analyze emissions reduction policies often leads to varying conclusions. For instance, this study examines the supply chain of typical agro-products, represented by yellow chives, and concludes that subsidies are best provided to logistic processes for emissions reduction. However, during the study by Smith et al. [40] on the supply chain of a bioenergy generated by anaerobic fermentation in Africa, it was found that government subsidies should most preferably cover some of the investments in related infrastructure development. Moreira et al. [41] used the 
ethanol supply chain in Brazil as an example and argued that the optimal government policy for emissions reduction is to pay both upstream and downstream industries a subsidy of \$10 USD per ton of carbon dioxide reduction. It is evident that different types of supply chains require different policies on emissions reduction. Second, the system boundaries also create uncertainties in the computation of carbon emissions. For example, in terms of electricity consumption, this study merely focuses on direct consumption, without further considering the indirect carbon emissions from secondary energy consumption by using electricity. In addition, the agro-product supply chain is highly uncertain and involves interaction among stakeholders. In particular, consumers' preferences and needs have yet to be effectively predicted. Whether government subsidies for bioenergy enterprises will result in rent-seeking behavior and dependence on the subsidies is yet to be examined.

\section{Conclusions}

Against the strategic background of the Belt and Road Initiative, this study redesigned a regional agro-product supply chain by taking bioenergy enterprises into account to reduce ago-wastes and enhance eco-efficiency. Two operational scenarios were created, in which Scenario 1 assumes that all the agro-waste flows into the bioenergy enterprise, whilst Scenario 2 only takes the agro-wastes produced by farmers and the wholesale market for energy production into account.

System dynamics offer a powerful tool to select the optimal scenario to enhance the eco-efficiency of the proposed supply chain. The simulation result shows that Scenario 2 has greater potential in improvement of the eco-efficiency of the agro-product supply chain, particularly reflected in its carbon emission reduction.

In order to drive such a scenario into management practice, an incentivizing mechanism was designed based upon governmental subsidy for the bioenergy enterprise or the logistic processes. The simulation result shows that subsidy for the logistic processes is better for facilitating supply chain operations. It is expected that the results may provide insight into the optimization of agro-product supply chain management in countries along the Belt and Road routes.

However, there are limitations to this study. For example, it concentrates on the effectiveness of emissions reduction without considering the marginal cost of such reduction. While focusing on the effects of incentivizing policies on the supply chain, it fails to consider other marketing measures. Future studies should determine the cost of carbon emission reduction in supply chains while coordinating and optimizing such emissions and incurred costs. They may even apply game theory to the interactive mechanism among stakeholders of an agro-product supply chain under different political contexts to facilitate policy implementation.

Acknowledgments: This study was sponsored by National Natural Science Foundation of China (No. 41571520; No. 71701029), Sichuan Provincial Key Technology Support (No. 18RKX0986), Sichuan Province Circular Economy Research Center Fund (No. XHJJ01) and Liaoning Province Philosophy and Social Science Planning Fund (No. L17BGL019), Fundamental Research Funds for the Central Universities (DUT16RC(3)038).

Author Contributions: Rui Zhao was involved in conceptualizing the whole study, proposing the closed-loop model for agro-product supply chain, and writing the whole paper. Yiyun Liu and Zhenyan Zhang sketched the system dynamics casual loop diagram and stock flow diagram. Sidai Guo conducted the case study to collect the data. Ming-Lang Tseng improved the whole structure of the paper. Kuo-Jui Wu implemented the calculation to verify the proposed model.

Conflicts of Interest: The authors declare no conflict of interest.

\section{Appendix A}

$$
\begin{gathered}
\operatorname{VFP}=\operatorname{IF} \text { THEN ELSE }(\operatorname{PIFS}<1000, \text { FFI } \times \operatorname{IPA}, 0) \\
\operatorname{PIFS}(\mathrm{n})=\operatorname{INTEGRAL}(\operatorname{VFP}(\mathrm{n})-\operatorname{VMA}(\mathrm{n})-\operatorname{VARF}(\mathrm{n}), \operatorname{PIFS}(0)) \\
\operatorname{PIFS}(0)=1000
\end{gathered}
$$




$$
\mathrm{FFI}=1 \times \text { FII }
$$

FII $=$ VFI $/$ DELAY1I(VFI, 1, 10 Million $)$

VFI $($ Variation of Farmers' Income $)=$ PP $($ Profit Per Product $) \times$ VMA

(Variation of Marketing Acquisition)

PP $($ Profit Per Product $)=$ AP $($ Acquisition Price $)-C($ Cost $)$

AP $($ Acquisition Price $)=<$ Time $>=([(0,0)-(10,10)],(1,5.5),(2,6),(3,7.5),(4,8),(5,9),(6,8.8)$,

$(7,10),(8,10),(9,10.2),(10,9))$

PP (Profit Per Product $)=$ C (Cost)

VMA $=$ IF THEN ELSE $($ PIFS $\leq 0,0$, IF THEN ELSE $($ PIMS $>$ INVENTORYCAPACITY, 0 ,

$$
\begin{gathered}
1000 \times \text { FMR }) \\
\text { FMR }=\text { MP }-\mathrm{AP}
\end{gathered}
$$

$\mathrm{FMR}=\mathrm{FMR} / \mathrm{DELAY} 1 \mathrm{I}(\mathrm{MR}, 1, \mathrm{MR}(0))$

$$
\operatorname{MR}(0)=1
$$$$
\operatorname{PIMS}(\mathrm{n})=\operatorname{INTEGRAL}(\operatorname{VMA}(\mathrm{N})-\operatorname{VCP}(\mathrm{n})-\operatorname{VWRM}(\mathrm{n}), \operatorname{PIMS}(0))
$$$$
\operatorname{PIMS}(0)=1000
$$

VCP $=$ IF THEN ELSE $($ PIMS $>0,1000 /($ FMP $\times$ FCD $), 0)$

FCD = PICS/DELAY1I(PICS, 1, VCP(0))

$$
\operatorname{VCP}(0)=0
$$

$\mathrm{FMP}=\mathrm{MP} / \mathrm{DELAY} 1 \mathrm{I}(\mathrm{MP}, 1, \mathrm{MP}(0))$

$$
\mathrm{MP}(0)=8
$$

$\mathrm{MP}($ Marketing Price $)=<$ Time $>=([(0,0)-(10,10)],(1,8),(2,9.7),(3,10),(4,10.8),(5,11),(6,10.6),(7,11.8)$, $(8,12),(9,13),(10,12.5))$

$$
\begin{gathered}
\operatorname{PICS}(\mathrm{n})=\operatorname{INTEGRAL}(\operatorname{VCFP}(\mathrm{N})-\operatorname{VC}(\mathrm{n})-\operatorname{VWGC}(\mathrm{n}), \operatorname{VCFP}(0)) \\
\operatorname{VCFP}(0)=100 \\
\operatorname{VECRL}=(\operatorname{PLRF} \times \operatorname{PIFS}+\operatorname{PLRM} \times \operatorname{PIMS}) \times \text { FECT } \\
\operatorname{ECRL}(\mathrm{n})=\operatorname{INTEGRAL}(\operatorname{VERAL}(\mathrm{n}), 0)
\end{gathered}
$$

In Scenario 1 of the redesigned supply chain,

$$
\mathrm{AL}=0, \mathrm{CELD}=0 .
$$

In Scenario 2 of the redesigned supply chain,

$$
\operatorname{AL}(\mathrm{n})=\operatorname{INTEGRAL}(\operatorname{VWGC}(\mathrm{n}), 0) \operatorname{CELD}(\mathrm{n})=\mathrm{AL}(\mathrm{n}) \times \operatorname{CEFL}
$$

VWGC (Variation of Waste Generation in Consuming Stage) $=$ VCP (Variation of

Consumers' purchasing) $\times$ PLRC (Product Loss Rate of Consuming Stage)

In Scenario 1 of the redesigned supply chain,

$$
\mathrm{VWRBP}=\mathrm{VARF}+\mathrm{VWRM},
$$




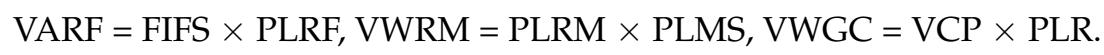

In Scenario 2 of the redesigned supply chain,

$$
\begin{aligned}
& \text { VWRBP }=\text { VARF }+ \text { VWRM, where VARF }=\text { FIFS } \times \text { PLRF, VWRM }=\text { PLRM } \times \text { PLMS } . \\
& \text { VEC }(\text { Variation of Energy Consumption })=\text { VECF }+ \text { VECT + VECM + VECRL }- \text { VBP } \\
& \text { TEC }(\text { Total Energy Consumption })=\operatorname{INTEGRAL}(\operatorname{VEC}(\mathrm{n}), \operatorname{VEC}(0)) \\
& \operatorname{VEC}(0)=0 \\
& \mathrm{VECF}=\mathrm{PIFS} \times \text { FECFS, VECT }=\text { FECT } \times \text { VMA, VECM }=\text { PIMS } \times \text { FECMS } \\
& \text { VCE (Variation of Carbon Emissions) }=\text { VCET (Variation of Carbon Emissions in } \\
& \text { Transportation) + VCEWT (Variation of Carbon Emissions in Waste Transportation) } \\
& \operatorname{TCE}(\mathrm{n})=\operatorname{INTEGRAL}(\operatorname{VCE}(\mathrm{n}), \operatorname{TCE}(\mathrm{n}-1)) \\
& \operatorname{TCE}(0)=1000 \\
& \text { VP (Variation of Total Products })=\text { VFP (Variation of Farmers' Production }) \\
& \operatorname{TAP}(\mathrm{n})=\operatorname{INTEGRAL}(\mathrm{VP}(\mathrm{n}), 0) \\
& \text { CEP }(\text { Carbon Emissions Per Product })=\text { TCE (Total Carbon Emissions }) / \text { TAP } \\
& \text { (Total Amount of Products) }
\end{aligned}
$$

\section{References}

1. Huang, Y. Understanding China's Belt \& Road Initiative: Motivation, framework and assessment. China Econ. Rev. 2016, 40, 314-321.

2. Zhang, N.; Liu, Z.; Zheng, X.; Xue, J. Carbon footprint of China's belt and road. Science 2017, $357,1107$. [CrossRef] [PubMed]

3. Chen, H. China's 'One Belt, One Road' initiative and its implications for Sino-African investment relations. Transnatl. Corp. Rev. 2016, 8, 178-182. [CrossRef]

4. Shaharudin, M.R.; Govindan, K.; Zailani, S.; Tan, K.C.; Iranmanesh, M. Product return management: Linking product returns, closed-loop supply chain activities and the effectiveness of the reverse supply chains. J. Clean. Prod. 2017, 149, 1144-1156. [CrossRef]

5. $\mathrm{Xu}, \mathrm{H}$. The Study on Eco-environmental Issue of Aral Sea from the Perspective of Sustainable Development of Silk Road Economic Belt. IOP Conf. Ser. Earth Environ. Sci. 2017, 57, 012060. [CrossRef]

6. Herbert, G.J.; Krishnan, A.U. Quantifying environmental performance of biomass energy. Renew. Sustain. Energy Rev. 2016, 59, 292-308. [CrossRef]

7. Motghare, K.A.; Rathod, A.P.; Wasewar, K.L.; Labhsetwar, N.K. Comparative study of different waste biomass for energy application. Waste Manag. 2016, 47, 40-45. [CrossRef] [PubMed]

8. AI-Hamamre, Z.; Saidan, M.; Hararah, M.; Rawajfeh, K.; Alkhasawneh, H.E.; AI-Shannag, M. Wastes and biomass materials as sustainable-renewable energy resources for Jordan. Renew. Sustain. Energy Rev. 2017, 67, 295-314. [CrossRef]

9. Sinclair, P.; Cohen, B.; Hansen, Y.; Basson, L.; Clift, R. Stakeholder engagement within the sustainability assessment of bioenergy: Case studies in heat, power and perennial and annual crops from the UK. Biomass Bioenergy 2015, 73, 11-22. [CrossRef]

10. Patrizio, P.; Leduc, S.; Chinese, D.; Kraxner, F. Internalizing the external costs of biogas supply chains in the Italian energy sector. Energy 2017, 125, 85-96. [CrossRef]

11. Tonelli, F.; Evans, S.; Taticchi, P. Industrial sustainability: Challenges, perspectives, actions. Int. J. Bus. Innov. Res. 2013, 7, 143-163. [CrossRef]

12. Xiao, Y.B.; Jian, C.; Xu, X.L. Fresh product supply chain coordination under CIF business model with long distance transportation. Syst. Eng. 2008, 28, 19-34. [CrossRef] 
13. Pathumnakul, S.; Piewthongngam, K.; Khamjan, S. Integrating a shrimp-growth function, farming skills information, and a supply allocation algorithm to manage the shrimp supply chain. Comput. Electron. Agric. 2009, 66, 93-105. [CrossRef]

14. Bohle, C.; Maturana, S.; Vera, J. A robust optimization approach to wine grape harvesting scheduling. Eur. J. Oper. Res. 2010, 200, 245-252. [CrossRef]

15. Paksoy, T.; Pehlivan, N.Y.; Özceylan, E. Application of fuzzy optimization to a supply chain network design: A case study of an edible vegetable oils manufacturer. Appl. Math. Model. 2012, 36, 2762-2776. [CrossRef]

16. De Keizer, M.; Haijema, R.; Bloemhof, J.M.; van der Vorst, J.G. Hybrid optimization and simulation to design a logistics network for distributing perishable products. Comput. Ind. Eng. 2015, 88, 26-38. [CrossRef]

17. Soto-Silva, W.E.; Nadal-Roig, E.; González-Araya, M.C.; Pla-Aragones, L.M. Operational research models applied to the fresh fruit supply chain. Eur. J. Oper. Res. 2016, 251, 345-355. [CrossRef]

18. Soysal, M.; Bloemhof-Ruwaard, J.M.; Van der Vorst, J.G.A.J. Modelling food logistics networks with emission considerations: The case of an international beef supply chain. Int. J. Prod. Econ. 2014, 152, 57-70. [CrossRef]

19. Accorsi, R.; Cholette, S.; Manzini, R.; Pini, C.; Penazzi, S. The land-network problem: Ecosystem carbon balance in planning sustainable agro-food supply chains. J. Clean. Prod. 2016, 112, 158-171. [CrossRef]

20. Chandrasekaran, M.; Chandrasekaran, M.; Ranganathan, R.; Ranganathan, R. Modelling and optimization of Indian traditional agriculture supply chain to reduce post-harvest loss and $\mathrm{CO}_{2}$ emission. Ind. Manag. Data Syst. 2017, 117, 1817-1841. [CrossRef]

21. Jonker, J.G.G.; Junginger, H.M.; Verstegen, J.A.; Lin, T.; Rodríguez, L.F.; Ting, K.C.; Faaij, A.P.C.; van der Hilst, F. Supply chain optimization of sugarcane first generation and eucalyptus second generation ethanol production in Brazil. Appl. Energy 2016, 173, 494-510. [CrossRef]

22. Miranda-Ackerman, M.A.; Azzaro-Pantel, C. Extending the scope of eco-labelling in the food industry to drive change beyond sustainable agriculture practices. J. Environ. Manag. 2017, 204, 814-824. [CrossRef] [PubMed]

23. Genovese, A.; Acquaye, A.A.; Figueroa, A.; Koh, S.L. Sustainable supply chain management and the transition towards a circular economy: Evidence and some applications. Omega 2017, 66, 344-357. [CrossRef]

24. Kim, T.; Glock, C.H.; Kwon, Y. A closed-loop supply chain for deteriorating products under stochastic container return times. Omega 2014, 43, 30-40. [CrossRef]

25. Turki, S.; Didukh, S.; Sauvey, C.; Rezg, N. Optimization and Analysis of a Manufacturing-RemanufacturingTransport-Warehousing System within a Closed-Loop Supply Chain. Sustainability 2017, 9, 561. [CrossRef]

26. Zabaniotou, A.; Rovas, D.; Libutti, A.; Monteleone, M. Boosting circular economy and closing the loop in agriculture: Case study of a small-scale pyrolysis-biochar based system integrated in an olive farm in symbiosis with an olive mill. Environ. Dev. 2015, 14, 22-36. [CrossRef]

27. Banasik, A.; Kanellopoulos, A.; Claassen, G.D.H.; Bloemhof-Ruwaard, J.M.; van der Vorst, J.G. Closing loops in agricultural supply chains using multi-objective optimization: A case study of an industrial mushroom supply chain. Int. J. Prod. Econ. 2017, 183, 409-420. [CrossRef]

28. Bianchi, N.P.; Evans, S.; Revetria, R.; Tonelli, F. Influencing factors of successful transitions towards product-service systems: A simulation approach. Int. J. Math. Comput. Simul. 2009, 3, 30-43.

29. Zhao, R.; Xi, B.; Liu, Y.; Su, J.; Liu, S. Economic potential of leachate evaporation by using landfill gas: A system dynamics approach. Resour. Conserv. Recycl. 2017, 124, 74-84. [CrossRef]

30. IPCC. Guidelines for National Greenhouse Gas Inventories; Eggleston, H.S., Buendia, L., Miwa, K., Ngara, T., Tanabe, K., Eds.; The National Greenhouse Gas Inventories Programme, IGES: Kanagawa, Japan, 2006; Available online: http:/ / www.ipcc-nggip.iges.or.jp/public/2006gl/index.htm (accessed on 26 January 2018).

31. Patel, H.K.; Kumar, S. Experimental analysis on performance of diesel engine using mixture of diesel and bio-diesel as a working fuel with aluminum oxide nanoparticle additive. Therm. Sci. Eng. Prog. 2017, 4, 252-258. [CrossRef]

32. Giordano, A.; Fischbeck, P.; Matthews, H.S. Environmental and economic comparison of diesel and battery electric delivery vans to inform city logistics fleet replacement strategies. Transp. Res. D Transp. Environ. 2017. [CrossRef]

33. Lee, U.; Han, J.; Wang, M. Evaluation of landfill gas emissions from municipal solid waste landfills for the life-cycle analysis of waste-to-energy pathways. J. Clean. Prod. 2017, 166, 335-342. [CrossRef]

34. Li, Z.; Shen, G.Q.; Alshawi, M. Measuring the impact of prefabrication on construction waste reduction: An empirical study in China. Resour. Conserv. Recycl. 2014, 91, 27-39. [CrossRef] 
35. Elsawah, S.; Pierce, S.A.; Hamilton, S.H.; Van Delden, H.; Haase, D.; Elmahdi, A.; Jakeman, A.J. An overview of the system dynamics process for integrated modelling of socio-ecological systems: Lessons on good modelling practice from five case studies. Environ. Model. Softw. 2017, 93, 127-145. [CrossRef]

36. Zhao, R.; Zhou, X.; Jin, Q.; Wang, Y.; Liu, C. Enterprises' compliance with government carbon reduction labelling policy using a system dynamics approach. J. Clean. Prod. 2017, 163, 303-319. [CrossRef]

37. He, Y.; Xu, Y.; Pang, Y.; Tian, H.; Wu, R. A regulatory policy to promote renewable energy consumption in China: Review and future evolutionary path. Renew. Energy 2016, 89, 695-705. [CrossRef]

38. Nguyen, L.; Cafferty, K.G.; Searcy, E.M.; Spatari, S. Uncertainties in life cycle greenhouse gas emissions from advanced biomass feedstock logistics supply chains in Kansas. Energies 2014, 7, 7125-7146. [CrossRef]

39. Yue, D.; You, F.; Snyder, S.W. Biomass-to-bioenergy and biofuel supply chain optimization: Overview, key issues and challenges. Comput. Chem. Eng. 2014, 66, 36-56. [CrossRef]

40. Smith, J.U.; Fischer, A.; Hallett, P.D.; Homans, H.Y.; Smith, P.; Abdul-Salam, Y.; Emmerling, H.H.; Phimister, E. Sustainable use of organic resources for bioenergy, food and water provision in rural Sub-Saharan Africa. Renew. Sustain. Energy Rev. 2015, 50, 903-917. [CrossRef]

41. Moreira, J.R.; Romeiro, V.; Fuss, S.; Kraxner, F.; Pacca, S.A. BECCS potential in Brazil: Achieving negative emissions in ethanol and electricity production based on sugar cane bagasse and other residues. Appl. Energy 2016, 179, 55-63. [CrossRef]

(C) 2018 by the authors. Licensee MDPI, Basel, Switzerland. This article is an open access article distributed under the terms and conditions of the Creative Commons Attribution (CC BY) license (http://creativecommons.org/licenses/by/4.0/). 